Canadian Journal of

Physiology

and Pharmacology

Revue canadienne de

physiologie

et pharmacologie
Volume 9 | An NRC Research

Press Journal

Une revue de

NRC Research

2013

Press
wWw.nrcresearchpress.com

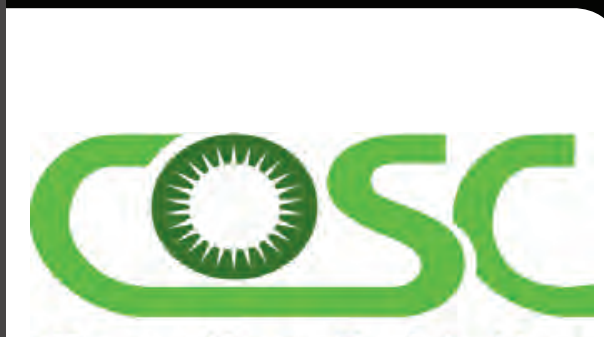

Canadian Oxidative Stress Consortium
Before

injection

$0 \mathrm{~min}$
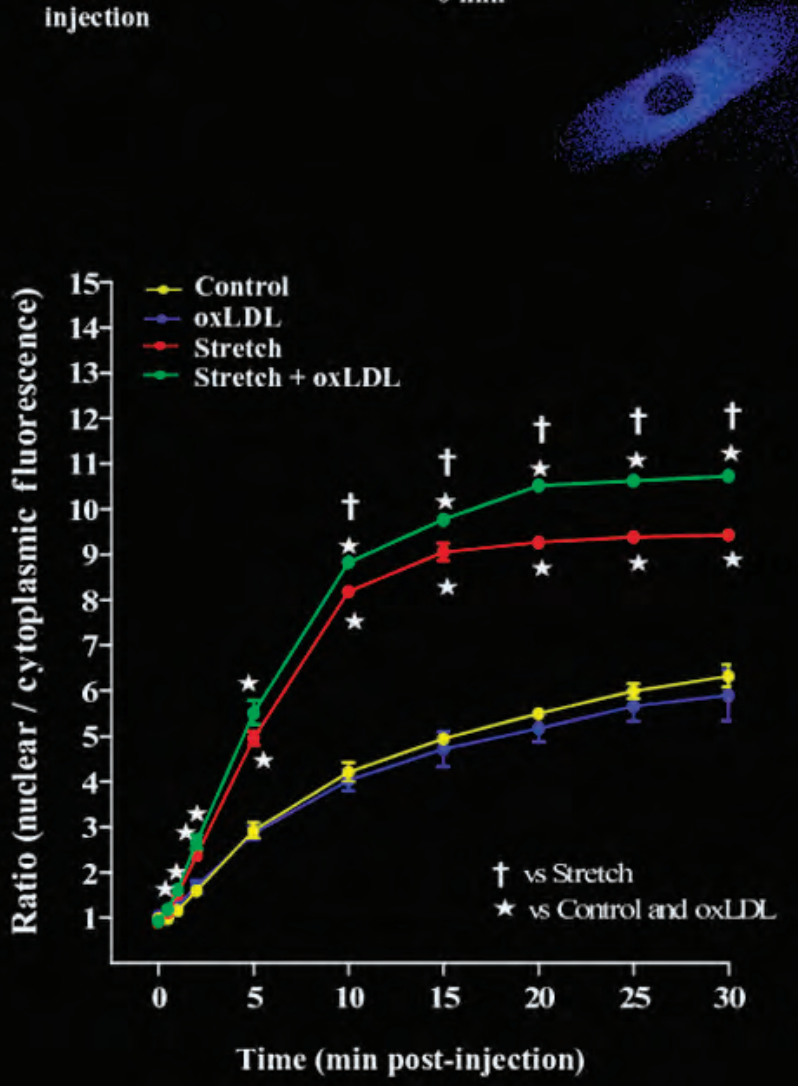

$5 \mathrm{~min}$

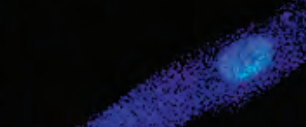

$5 \mathrm{~min}$

$5 \mathrm{~min}$

5 min

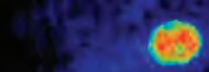

$30 \mathrm{~min}$

30 min

$30 \mathrm{~min}$

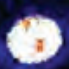

In cooperation with

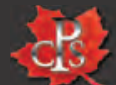

and

Canadian Society of Pharmacology and Therapeutics
Avec le concours de la

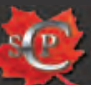

et de la

Société canadienne de pharmacologie et de thérapeutique
NRC

Research Press 


\title{
Altered expression of genes for Kir ion channels in dilated cardiomyopathy ${ }^{1}$
}

Viktoria Szuts, Dalma Ménesi, Zoltán Varga-Orvos, Ágnes Zvara, Nazanin Houshmand, Miklós Bitay, Gábor Bogáts, László Virág, István Baczkó, Balázs Szalontai, Amir Geramipoor, Diego Cotella, Erich Wettwer, Ursula Ravens, Ferenc Deák, László G. Puskás, Julius Gy. Papp, Ibolya Kiss, András Varró, and Norbert Jost

\begin{abstract}
Dilated cardiomyopathy (DCM) is a multifactorial disease characterized by left ventricular dilation that is associated with systolic dysfunction and increased action potential duration. The Kir2.x $\mathrm{K}^{+}$channels (encoded by KCNJ genes) regulate the inward rectifier current $\left(I_{\mathrm{K} 1}\right)$ contributing to the final repolarization in cardiac muscle. Here, we describe the transitions in the gene expression profiles of $4 \mathrm{KCNJ}$ genes from healthy or dilated cardiomyopathic human hearts. In the healthy adult ventricles, KCNJ2, KCNJ12, and KCNJ4 (Kir2.1-2.3, respectively) genes were expressed at high levels, while expression of the KCNJ14 (Kir2.4) gene was low. In DCM ventricles, the levels of Kir2.1 and Kir2.3 were upregulated, but those of Kir2.2 channels were downregulated. Additionally, the expression of the DLG1 gene coding for the synapse-associated protein 97 (SAP97) anchoring molecule exhibited a 2 -fold decline with increasing age in normal hearts, and it was robustly downregulated in young DCM patients. These adaptations could offer a new aspect for the explanation of the generally observed physiological and molecular alterations found in DCM.
\end{abstract}

Key words: inward rectifier potassium channels, $I_{\mathrm{K} 1}$, dilated cardiomyopathy, Kir2.x, SAP97.

Résumé : La cardiomyopathie dilatée (CMD) est une maladie multifactorielle caractérisée par une dilatation du ventricule gauche associée à une dysfonction systolique et à une augmentation de la durée du potentiel d'action. Les canaux potassiques Kir2.x (codés par les gènes KCNJ) régulent le courant rectifiant entrant $\left(\mathrm{I}_{\mathrm{KI}}\right)$, contribuant à la repolarisation finale du muscle cardiaque. Nous décrivons ici la transition des profils d'expression génique de quatre KCNJ à partir du cœur d'individus normaux vers des cœurs cardiomyopathiques dilatés. Les gènes KCNJ2, KCNJ12 et KCNJ4 (Kir2.1-2.3) étaient exprimés à des niveaux élevés dans les cœurs non malades, alors que l'expression du gène KCNJ14 (Kir2.4) était faible. Les niveaux de Kir2.1 et Kir2.3 étaient régulés à la hausse dans la CMD mais ceux des canaux Kir2.2 étaient diminués. De plus, l'expression du gène DLG1 qui code la protéine associée au synapse SAP97, une protéine d'ancrage, était diminuée de 2 fois en fonction de l'augmentation de l'âge des individus dont le cœur est normal, et elle était fortement diminuée chez les jeunes patients atteints de CMD. Ces adaptations pourraient offrir un constituer une nouvelle façon d'expliquer les modifications physiologiques et moléculaires généralement observées dans la CMD. [Traduit par la Rédaction]

Mots-clés : canaux potassiques rectifiants entrants, $I_{\mathrm{KI}}$, cardiomyopathie dilatée, Kir2.x, SAP97.

\section{Introduction}

Dilated cardiomyopathy (DCM) is a myocardial disorder characterized by left ventricular dilation and systolic dysfunction often leading to progressive heart failure, arrhythmias, and premature death (Csanády et al. 1991; Jefferies and Towbin 2010). DCM is associated with increased action potential duration and decreased resting membrane potential, and the whole-cell current slope conductance in cells of DCM is smaller than that for donor or ischemic cardiomyopathy (Koumi et al. 1995). As a chronic multifactorial disease, DCM is likely to affect multiple clusters of genes. Marked alterations were observed in the characteristics of the inward rectifier potassium current $\left(I_{\mathrm{K} 1}\right)$, but not in the sodium current $\left(I_{\mathrm{Na}}\right)$ in ventricular myocytes of DCM patients compared with healthy donors (Koumi et al. 1995). The $I_{\mathrm{K} 1}$ current plays a major role in maintaining the cellular resting membrane potential, and it is involved in the consequences of DCM such as the arrhythmogenesis of coronary artery disease and ventricular arrhythmias with sudden cardiac death (Csanády et al. 1991; Hibino et al. 2010). However, the molecular mechanisms underlying these alterations of $I_{\mathrm{K} 1}$ are still largely unknown.

The $I_{\mathrm{K} 1}$ current is conducted via ion channels consisting of heteromeric assemblies of Kir2.1, Kir2.2, and Kir2.3 $\alpha$-subunits (Marban 2002; Rook 2007). To shed more light on the contribution of $\alpha-, \beta-$, and auxiliary subunits of Kir channels to the pathomechanism of DCM, we studied the alterations in gene expression at the RNA and protein level in DCM diseased hearts compared with healthy controls.

Received 2 November 2012. Accepted 19 February 2013.

V. Szuts, F. Deák, and I. Kiss. Institute of Biochemistry, Biological Research Centre, Hungarian Academy of Sciences, Szeged, Hungary.

D. Ménesi, Z. Varga-Orvos, Á. Zvara, and L.G. Puskás. Institute of Genetics, Biological Research Centre, Hungarian Academy of Sciences, Szeged, Hungary.

N. Houshmand. Department of Dermatology and Allergology, Faculty of Medicine, University of Szeged, Hungary.

M. Bitay and G. Bogáts. Department of Cardiac Surgery, 2nd Department of Internal Medicine and Cardiological Center, Faculty of Medicine, University of Szeged, Hungary.

L. Virág, J.G. Papp, A. Varró, and N. Jost. Department of Pharmacology and Pharmacotherapy, Faculty of Medicine, University of Szeged, Hungary; Division of Cardiovascular

Pharmacology, Hungarian Academy of Sciences, Szeged, Hungary.

I. Baczkó and A. Geramipoor. Department of Pharmacology and Pharmacotherapy, Faculty of Medicine, University of Szeged, Hungary.

B. Szalontai. Institute of Biophysics, Biological Research Centre, Hungarian Academy of Sciences, Szeged, Hungary.

D. Cotella. Department of Medical Sciences, University of Eastern Piedmont, Novara, Italy.

E. Wettwer and U. Ravens. Department of Pharmacology and Toxicology, University of Technology, Dresden, Germany.

Corresponding author: Norbert Jost (e-mail: jost.norbert@med.u-szeged.hu).

${ }^{1}$ This article is one of a selection of papers published in the special issue on Sudden Cardiac Death and Cardioprotection. 
$I_{\mathrm{K} 1}$ can strongly influence the final repolarization in cardiac muscle (Muňoz et al. 2007). It also regulates diastolic membrane conductance (Rook 2007). The current is active during the action potential (AP), but the molecular basis is poorly characterized. $I_{\mathrm{K} 1}$ is underlain mostly by Kir2.x (Kir2.1, Kir2.2, and Kir2.3) ion channels (Karle et al. 2002; Marban 2002; Rook 2007). Earlier, the asymmetrical distribution and apico-basal inhomogeneity of Kir ion channels were investigated by Szabó et al. (2005) and Szentadrassy et al. (2005). They found that there are no transmural differences, at the protein level, in Kir2.1 channels in human and dog ventricles.

The expression and properties of the abovementioned $\mathrm{K}^{+}$channels are altered in cardiac diseases (i.e., Andersen's syndrome, cardiac arrhythmia, long QT syndromes, hypertrophic cardiomyopathy, and heart failure) (Marban 2002; Gaborit et al. 2009).

Kir-type ion channels share structural similarities (Anumonwo and Lopatin 2010) and have a role in a wide variety of physiological functions including insulin release, vascular tone, heart rate, buffering of potassium, and renal salt flow (Kubo et al 2005; Gaborit et al. 2009). These ion channels strongly modulate cell excitability and repolarization of AP, and determine the cellular resting membrane potential (Muňoz et al. 2007; Anumonwo and Lopatin 2010). Kir2.x subunits (Kir2.1, Kir2.2, Kir2.3, and Kir2.4), encoded by the KCNJ2, KCNJ12, KCNJ4, and KCNJ14 genes, respectively, assemble to form homo- or hetero-tetrameric inward rectifier potassium channels in cardiomyocytes. These channels are essential for generation of the $I_{K 1}$ current, which is tightly but differentially regulated within the diverse regions of the heart. The expression pattern of translated Kir2.x channel isoforms may determine the properties of both inward and outward components of $I_{\mathrm{K} 1}$ (Warren et al. 2003).

The physiological functions of ion channels are strongly influenced by intracellular scaffolding, trafficking, and regulatory proteins. It has recently been demonstrated that the Kir2.1, Kir2.2, and Kir2.3 isoforms colocalize with membrane-associated guanylate kinase (MAGUK) proteins such as synapse-associated protein 97 (SAP97) and postsynaptic density protein 95 (PSD-95) in cardiac muscle (Leonoudakis et al. 2000, 2004). Evidence has accumulated indicating that the Kir2.x isoforms interact with protein complexes that may be important to target and traffic ion channels and anchor and stabilize the channels in the plasma membrane (Vaidyanathan et al. 2010). The altered function found in DCM patients may lead to severe heart diseases, even sudden death.

To shed more light on the molecular basis of DCM, here we addressed the disease-related alterations in the expression of potassium channels and the related genes. Using quantitative real-time reverse transcriptase PCR (qRT-PCR) and Western blot analysis, we found characteristic differences between DCM patients and healthy controls, respectively, in the steady-state mRNA and protein levels for pore forming $\alpha$-, $\beta$-, and auxiliary subunits of $I_{\mathrm{K} 1}$ channels and their interacting partners. As a novel finding, we observed age-dependent expression of the DLG1 gene coding for SAP97 in healthy donor hearts and its robust downregulation in DCM. Furthermore, the subcellular distribution of Kir2.X-SAP97 complexes was also altered in the DCM ventricle. Our data suggest that the SAP97-regulated assembly of Kir2.x channels markedly contributes to $I_{\mathrm{K} 1}$, and that this assembly can be altered in diseased states such as DCM.

\section{Materials and methods}

\section{Human patients}

Hearts were obtained from organ donors whose hearts were explanted to obtain pulmonary and aortic homografts for valve surgery. Before cardiac explantation, organ donors $(n=31)$ did not receive medication apart from dobutamine, furosemide, and plasma expanders. The investigations conform to the principles of the Declaration of Helsinki. Experimental protocols were approved by the University of Szeged and National Scientific and Research Ethical Review Boards (No. 51-57/1997 OEj and 4991-0/2010-1018EKU (339/PI/010.)). Before explantation, each heart was perfused with cardioplegic solution (University of Debrecen, Medical and Health Science Center, Hungary) and kept cold $\left(4-6^{\circ} \mathrm{C}\right)$ for $2-4 \mathrm{~h}$ prior to dissection (Gaborit et al. 2009). Failing heart tissues were obtained from patients with diagnosed DCM who underwent heart transplantation and had end-stage heart failure (class III or IV heart failure according to the New York Heart Association). The DCM patients were 4 females and 13 males aged between 13-55 years (average $41.53 \pm 14.50$ years). The clinical treatment of patients whose heart tissues were studied is described in the Supplementary data, ${ }^{2}$ Table $S 1$. Left ventricular biopsy samples were dissected from the free wall of healthy donor hearts and patients with DCM, and represented the epi-, mid-, and endocardial layers.

\section{Whole-cell patch-clamp technique and electrophysiological recordings}

Cardiomyocytes were isolated from left ventricular tissues (31 healthy donors and 4 failing) by enzymatic dissociation, as previously described (Virág et al. 2002; Jost et al. 2009). HEPESbuffered Tyrode's solution (composition in mmol/L: $144 \mathrm{NaCl}$, $0.33 \mathrm{NaH}_{2} \mathrm{PO}_{4}, 4.0 \mathrm{KCl}, 1.8 \mathrm{CaCl}_{2}, 0.53 \mathrm{MgCl}_{2}, 5.5$ glucose, and 5.0 HEPES, pH 7.4) served as the normal superfusate. For measuring potassium currents, electrodes were filled with a solution containing (in mmol/L) $100 \mathrm{~K}$-aspartate, $45 \mathrm{KCl}, 10$ EGTA, $5 \mathrm{~K}_{2}$ ATP, 5 HEPES, and $1 \mathrm{MgCl}_{2}, \mathrm{pH}$ adjusted to 7.2 with $\mathrm{KOH}$ (Jost et al. 2009). All reagents were purchased from Sigma-Aldrich, St. Louis, Missouri, USA.

Membrane currents were recorded with Axopatch-1D and Axopatch-200B amplifiers (Molecular Devices Inc., Sunnyvale, California, USA) using the whole-cell configuration of the patchclamp technique. The cell capacitance was calculated by integrating the area under an uncompensated capacity transient, elicited by a $10 \mathrm{mV}$ hyperpolarizing pulse from $-10 \mathrm{mV}$, while the holding potential was $-90 \mathrm{mV}$. Membrane currents were digitized using a $333 \mathrm{kHz}$ analogue-to-digital converter (Digidata 1200 and 1320, Molecular Devices, Inc.) under software control (pClamp 6.0 and pClamp 8.0, Molecular Devices, Inc.). Analysis was performed using pClamp 6.0 and pClamp 8.0 software after low-pass filtering at $1 \mathrm{kHz}$. All experimental data were collected at $37^{\circ} \mathrm{C}$.

All data are presented as the mean \pm SEM. Statistical analysis was performed using Student's paired and unpaired $t$ tests. Values for $p<0.05$ were considered statistically significant.

\section{qRT-PCR}

RNA samples were isolated using the RNeasy Fibrous Tissue kit (Qiagen). Total RNA concentration and quality were determined using a NanoDrop ND-1000 spectrophotometer, and the integrity of all total RNA samples was confirmed by measuring 18S rRNA content. For in vitro reverse transcription, $2 \mu \mathrm{g}$ of total RNA was reverse transcribed using the Stratagene Reverse Transcriptase kit (Invitrogene, BioMedica Hungarian Ltd., Hungary) following the manufacturer's instruction manual $\left(25^{\circ} \mathrm{C}\right.$ for $10 \mathrm{~min}, 37^{\circ} \mathrm{C}$ for $120 \mathrm{~min}, 85^{\circ} \mathrm{C}$ for $5 \mathrm{~min}$, and kept at $4{ }^{\circ} \mathrm{C}$ ) (Zvara et al. 2005).

Each RNA sample was tested for the presence of genomic DNA contamination. Gene-specific primers were designed using Primer Express software (PE Applied Biosystems, Life Technologies) according to the software guidelines. These primers (listed in the Supplementary data, ${ }^{2}$ Table S2) were purchased from Avidin Ltd. (Szeged, Hungary). Quantitative reverse transcription PCR was

\footnotetext{
${ }^{2}$ Supplementary data are available with the article through the journal Web site at http://nrcresearchpress.com/doi/suppl/doi/10.1139/cjpp-2012-0413.
} 
carried out using the Brillant II SYBRGreen QPCR master mix kit (Stratagene, Agilent Technologies) following the manufacturer's instruction manual. PCR reactions were then performed first on the Open Array platform (OpenArray system formerly Biotrove, now Applied Biosystems, Life Technologies; 12 healthy (control) and 12 diseased (DCM)) and then validated with the Rotor Gene 3000 (Corbett Research, Australia; 31 control and 17 DCM patients).

Specific primers, selected for their cardiac expression, were designed for the following Kir ion channel coding genes: Kir2.1, Kir2.2, Kir2.3, Kir2.4 (KCNJ2, KCNJ12, KCNJ4, and KCNJ14), Kir3.1, Kir3.4, Kir6.1, and Kir 6.2 (as listed in the Supplementary data, ${ }^{2}$ Table S3); SUR1, SUR2 (KCNJ3, KCNJ5, KCNJ8, KCNJ9 and ABCC8, ABCC9); $\mathrm{K}^{+}$channel $\alpha$ - and $\beta$-subunits; SAP97 (DLG1); 8 marker genes for ubiquitin carboxyl-terminal esterase L1 (ubiquitin thiolesterase, UCHL1) and interleukin-6 (Barrans et al. 2002; Borlak and Thum 2003; Gaborit et al. 2007, 2009; Soltysinska et al. 2009); 3 hypertrophy as well as end-stage markers for atrial natriuretic peptide precursor, brain natriuretic peptide precursors, and $\beta$-myosin heavy chain; and 4 reference genes for normalization ((i) hypoxanthine-guanine phosphoribosyltransferase (HPRT), (ii) glycerol-6-phosphate dehydrogenase (GAPDH), (iii) S18, and (iv) $\beta$-actin (ACTB)).

All data were collected with instrument spectral compensation with Rotor Gene 3000 SDS 2.1 software and analyzed with the threshold cycle $\left(C_{\mathrm{T}}\right)$ relative-quantification method (Livak and Schmittgen 2001). The most uniformly distributed genes, HPRT and GAPDH, were selected for data normalization (for comparison with the literature). The relative expression of each gene versus HPRT and (or) GAPDH was calculated for each sample $\left(\Delta C_{\mathrm{T}}\right.$ indicates normalized data).

Data were analyzed in 2 independent ways: (i) Open Array software was applied to the gene expression profile; (ii) then Kir2.x and SAP97 mRNA levels were validated with qRT-PCR using the Rotor Gene 3000 version 6.0 software. For each compartment, the relative expression of each gene versus HPRT ( $2^{-\Delta C_{\mathrm{T}}}$ values) and (or) GAPDH were calculated. Throughout the paper, values are presented as the mean \pm SEM. Data for the healthy hearts compared with the DCM samples were calculated by the Pfaffl method, as previously described (Pfaffl 2001; Zvara et al. 2005). Pair-wise comparisons between cardiac compartments were conducted on within-patient matched samples by Student's paired $t$ tests $(p<0.05$ considered significant, $n=12-17)$. Unpaired $t$ tests were used for unmatched samples. The repeated measurements were analyzed by ANOVA followed by Bonferroni's multiple comparison post-hoc tests.

\section{Western blot analysis}

Membrane proteins were extracted from the ventricle of human healthy donor or DCM hearts using lysis buffer. Aliquots of equal protein content were separated using $8 \%$ SDS-PAGE and transferred to polyvinylidene difluoride filters (EMD Millipore) at $280 \mathrm{~mA}$ for $2.5 \mathrm{~h}$ at $4{ }^{\circ} \mathrm{C}$ to evaluate immunoreactivity. Membranes were blocked to prevent nonspecific binding. All materials were purchased from Sigma-Aldrich. The filters were incubated overnight at $4{ }^{\circ} \mathrm{C}$ with primary antibodies in Tris buffer supplemented with Tween-20. The antibodies used were as follows: anti-Kir2.1, anti-Kir2.2, anti-Kir2.3 (diluted 1:100; all from Alomone, Jerusalem), anti-Kir2.4 (diluted 1:100; SantaCruz), anti-SAP97 (diluted 1:300; LifeSpan, Bioscience Ltd., Hungary), anti- $\alpha$-actin (diluted 1:500; Dako Corporation), and anti-GAPDH (diluted 1:5000; SigmaAldrich). Filters were then washed and incubated with horseradishperoxidase-conjugated IgG (Dako Corporation, Agilent Technologies, or Sigma-Aldrich) specific to the source of the primary antibody. The immune complexes were detected using the ECL Western blotting detection system (Amersham Pharmacia Biotech, UK) following the manufacturer's instructions. The membranes, stripped at $60{ }^{\circ} \mathrm{C}$ for $30 \mathrm{~min}$ in stripping buffer $(100 \mathrm{mmol} / \mathrm{L}$ 2-mercapto-ethanol and $62.5 \mathrm{mmol} / \mathrm{L}$ Tris-HCl, $\mathrm{pH}$ 7.6), were reprobed with anti-GAPDH and (or) anti- $\alpha$-actin antibody to normalize for loading differences.

\section{Data analysis of bands}

$\mathrm{X}$-ray films (Kodak) were scanned and evaluated with Image J software verision 1.32 (NIH, www.nih.gov). The densities of specific bands were measured and corrected for the densities of GAPDH on the same membrane. Corrected optical densities were calculated and the differences between healthy and DCM samples were evaluated using ANOVA and Student's $t$ test. Data are represented as the mean \pm SEM.

\section{Immunofluorescence}

Cryostat sections $(10 \mu \mathrm{m})$ of healthy and DCM heart ventricle biopsies were treated with $0.5 \%$ collagenase, blocked with $2 \%$ BSA in calcium-free PBS, and incubated for $2 \mathrm{~h}$ at room temperature with rabbit anti-Kir2.x (diluted 1:100; Alomone and Sigma-Aldrich) and mouse anti-SAP97 antibodies (diluted 1:300; LifeSpan, BioMedica, Ltd.). Sections were then washed and incubated with Alexa 488-labelled anti-rabbit IgG (diluted 1:400; Molecular Probes) plus Cy3-conjugated anti-mouse IgG (diluted 1:400; Jackson ImmunoResearch Laboratories, Inc.) for $1 \mathrm{~h}$ at room temperature. Nuclei were stained with $1 \mu \mathrm{g} / \mathrm{mL}$ Hoechst 33258 in PBS for 10 min (method was modified after Piecha et al. (1999)). After rinsing, the sections were mounted with fluorescent mounting medium (Dako Corporation, Agilent Tech.) and then viewed and photographed using a Nikon Eclipse E600 epifluorescence microscope equipped with a Spot RT Slider camera, or using an Olympus Fluoview FV1000 confocal laser scanning microscope (Olympus Life Science Europa GmbH, Hamburg, Germany). Each specimen ( $n=2-3$ for each anti-Kir2.x antibody staining), was magnified $20 x-80 x$ and the field images were selected from the free wall of ventricles to represent the variability in Kir2.x expression.

\section{Results}

\section{Testing DCM samples for characteristic marker gene} expression

To confirm the diseased status, several marker genes known to be associated with heart disease were selected and the relative mRNA levels were checked in the left ventricle of the DCM hearts. As in previous reports (Barrans et al. 2002; Borlak and Thum 2003; Gaborit et al. 2007, 2009; Soltysinska et al. 2009), steady-state mRNA levels for atrial natriuretic peptide precursors (NPPA) and brain natriuretic peptide precursors $(N P P B)$ were increased $>5$-fold and 3.5-fold, respectively, in DCM patients relative to the controls (Fig. 1a). A significant increase was also found for ubiquitin carboxyl-terminal esterase L1 (ubiquitin thiolesterase, UCHL1) (Fig. 1b), whereas mRNA levels for $\beta$-myosin heavy chain did not change significantly in the left ventricle of DCM hearts compared with the healthy hearts. As expected, relative mRNA levels for interleukin- 6 and $\beta$-actin were significantly lower in DCM patients than in controls.

To bridge over the differences in previous studies (Barrans et al. 2002; Borlak and Thum 2003; Soltysinska et al. 2009), we were interested in inspecting the molecular basis of the $I_{\mathrm{K} 1}$ current in DCM.

\section{Disease-related changes in mRNA and protein levels of Kir2.x isoforms}

Cardiac left ventricular samples were obtained from 12 hearts of DCM patients and compared with those of 12 healthy donors. As a first step, we determined the relative mRNA levels for $\mathrm{K}^{+}$ion channel $\alpha$-subunits Kir2.1, Kir3.1, Kir3.4, Kir6.1, and Kir 6.2 as well as for $\beta$-subunits SUR1 and SUR2 by a high-throughput technique using the Open Array platform (designed in our laboratory). We observed marked changes in the relative mRNA levels of $I_{\mathrm{K}^{-}}{ }^{-}$ related genes in the ventricle of DCM patients compared with 
Fig. 1. Marker gene expression in the left ventricle of dilated cardiomyopathic (DCM) hearts. Relative mRNA levels for the indicated markers were determined by qRT-PCR in the left ventricle of DCM hearts and compared with those in healthy hearts. (a) Relative mRNA levels for atrial natriuretic peptide precursors (ANPP) and brain natriuretic peptide precursors (BNPP) were increased $>5$-fold and 3.5 -fold ( $p \leq 0.01$ ), respectively, while $\beta$-actin was decreased in DCM samples $(p<0.05)$. $\beta$ MHC, $\beta$-myosin heavy chain. (b) Interleukin-6 (IL-6) and ubiquitin carboxyl-terminal esterase L1 (UCHL-1) expression were significantly $(p \leq 0.01)$ lower and higher, respectively, in DCM ventricles compared with control hearts. (c) The mRNA expression pattern of $I_{\mathrm{K} 1}$-related genes for Kir channel $\alpha$-subunits and associated subunits. Bars, calculated as relative mRNA of Kir channels versus hypoxanthine-guanine phosphoribosyltransferase (HPRT), show the mean \pm SE of 3 independent experiments conducted in duplicate.

a

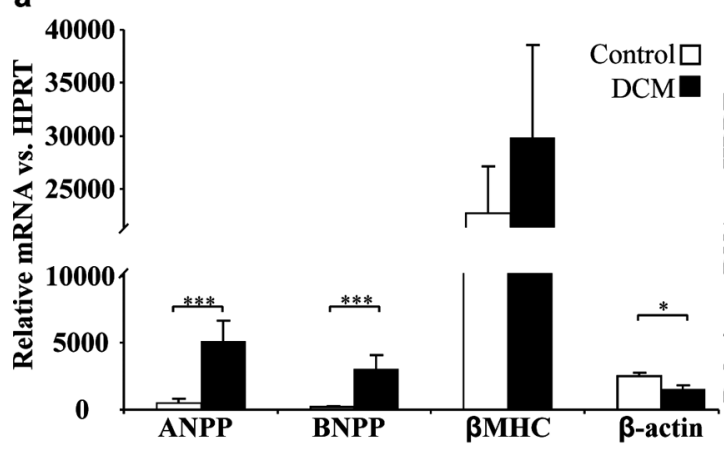

b

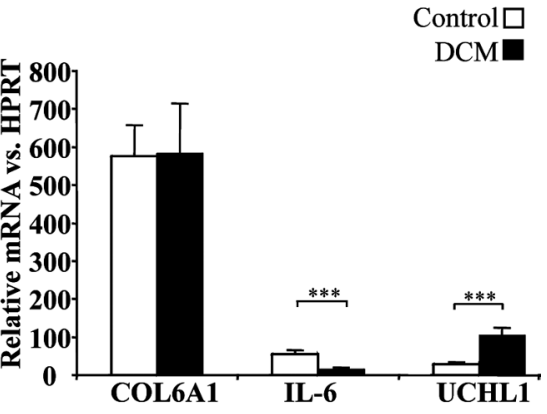

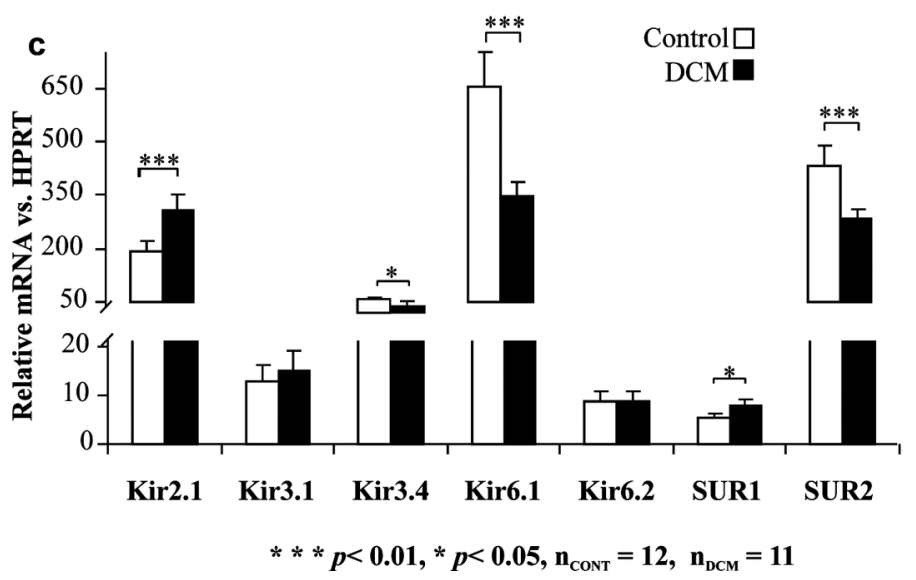

controls (Fig. 1c). Thus, Kir2.1 and SUR1 mRNA levels increased, while those for the Kir6.1 $\alpha$-subunit and SUR2 $\beta$-subunit were decreased relative to healthy controls. The relative mRNA level for Kir3.4 was also reduced in DCM patients, whereas the mRNA levels of Kir3.1 and Kir6.2 did not differ between the hearts of control and DCM patients (Fig. 1c).

Following nanomole scale qRT-PCR screening of Kir2.x isoforms, the most important differences in gene expression were verified by a conventional qRT-PCR assay, using a different set of primers. The sample sources were extended to left ventricles of 17 DCM patients and 15 healthy donors. We also investigated the protein levels using immunoblotting and immunofluorescence methods.

As Kir2.1, Kir2.2, and Kir2.3 are known to contribute markedly to the repolarization phase of APs in cardiomyocytes, we validated the alterations in the steady-state levels of mRNAs encoding these $\mathrm{K}^{+}$channel subunits in the heart of DCM patients. The data were normalized to both HPRT and GAPDH mRNA levels and showed similar differences between DCM and control heart samples (Figs. $2 a$ and $2 b$ ). Since mRNA levels for Kir channel subunits were commensurable with HPRT transcripts, but did not reach $1 \%$ of GAPDH mRNA levels, only mRNA levels relative to those of HPRT are presented in the rest of the paper. Extended analysis confirmed that both Kir2.1 and Kir2.3 mRNA levels were significantly elevated in DCM hearts compared with the controls (Figs. $2 a$ and $2 b$ ). The Kir2.4 mRNA level also increased in diseased ventri- cles. In contrast, the Kir2.2 transcript was significantly downregulated in DCM.

Next, we performed immunoblotting analysis of protein samples matching the RNA sources to reveal whether differences in steady-state mRNA levels were manifested in protein content. As expected, anti-human Kir2.1, Kir2.2, and Kir2.3 antibodies recognized bands of 55, 45, and $57 \mathrm{kDa}$, respectively (Fig. 3a). Kir2.1 protein expression was increased in the ventricles of DCM hearts thus confirming the mRNA data. Immunoblots were reprobed with anti-GAPDH and (or) $\alpha$-actin antiserum, and the intensity of immunosignals was then quantified by image analysis software relative to GAPDH or $\alpha$-actin internal controls (Figs. $3 b$ and $3 c$ ). The normalized protein amount of the Kir2.1 isoform was higher (by $\sim 70 \%$ ) showing some individual variability, while the Kir2.2 isoform was lower (by 29\%) in DCM compared with control hearts. The Kir2.3 protein content, however, did not differ considerably between donor and DCM ventricular tissue samples.

Thus, qRT-PCR analysis confirmed that mRNA expression for Kir2.1 (KCNJ2), Kir2.3 (KCNJ4), and Kir2.4 (KCNJ14) coding genes significantly increased (2.26-, 1.94-, and 1.6-fold, respectively), while the mRNA level for Kir2.2 (KCNJ12) was reduced to 66\% in DCM ventricles compared with the controls. In agreement with the RNA data, Western blot analysis revealed increased Kir2.1 and decreased Kir2.2 protein levels in DCM patients, but the Kir2.3 level was not markedly altered compared with the controls. 
Fig. 2. Relative mRNA levels for Kir2.x isoforms and synapse-associated protein 97 (SAP97) validated by qRT-PCR. (a) mRNA analysis confirmed that both Kir2.1 and Kir2.3 mRNA levels were significantly elevated in dilated cardiomyopathic (DCM) hearts compared with controls. Values of mRNA for Kir2.1-Kir2.4 were normalized to hypoxanthine-guanine phosphoribosyltransferase (HPRT). (b) mRNA levels for Kir2.x isoforms relative to those of GAPDH were measured by $-\Delta \Delta C_{\mathrm{T}}$ values. (c) Gene expression for SAP97 in the human left ventricle of healthy and DCM patients $\left(n_{\mathrm{CONT}}=31\right.$ and $\left.n_{\mathrm{DCM}}=17\right) .{ }^{*}, p<0.05$ compared with the control. (d) Age-dependent expression of SAP97 mRNA in donor and DCM hearts $\left(n_{\mathrm{CONT}}=31\right.$ and $\left.n_{\mathrm{DCM}}=17\right)$; ${ }^{*}, p<0.05$; NS, no significant difference. Values are expressed as the mean \pm SEM.
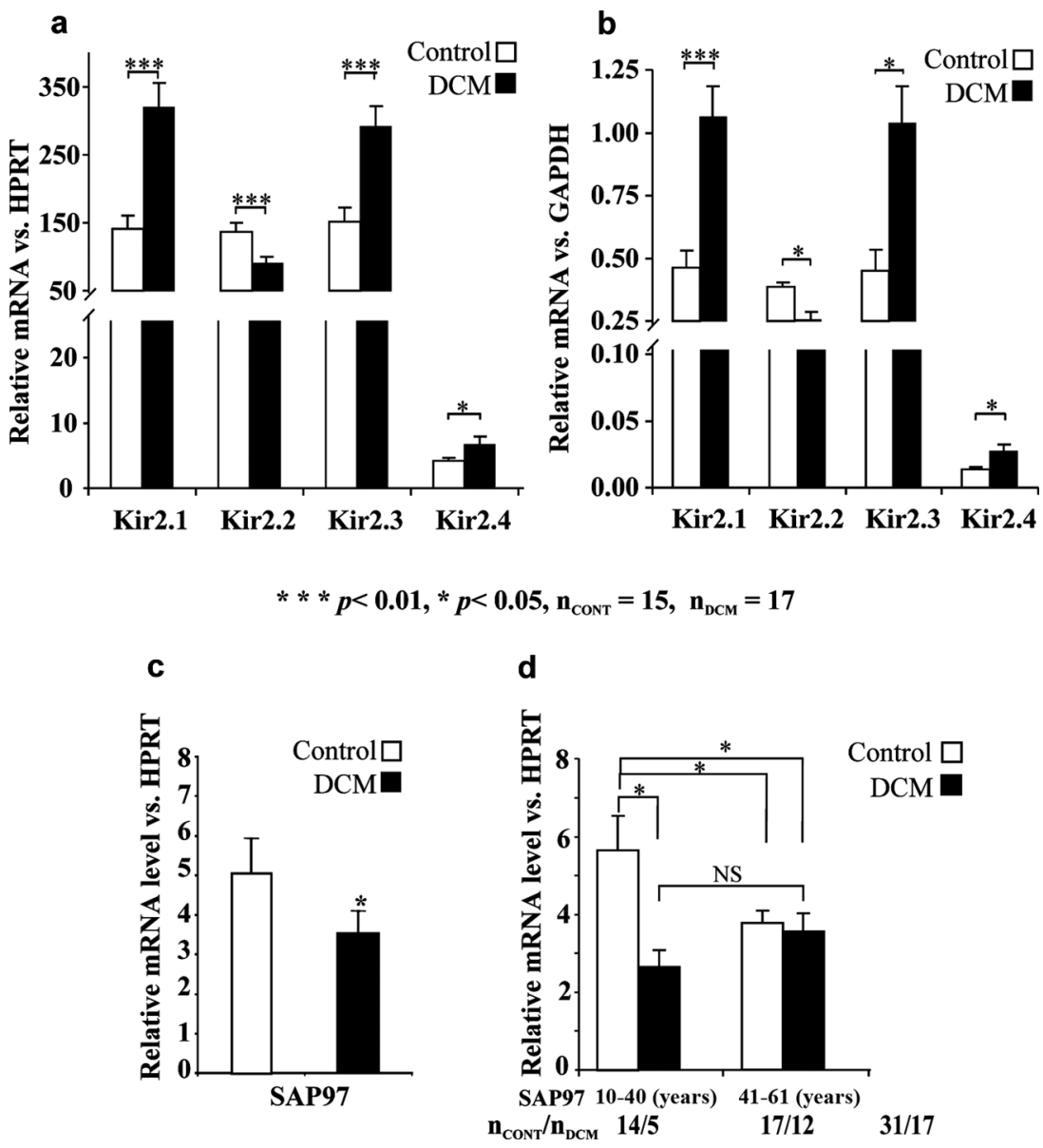

\section{Age-dependent and DCM-related changes in SAP97 mRNA} expression

Considering that SAP97 can associate with Kir2.2 and Kir2.3 isoforms in the heart samples (Leonoudakis et al. 2000, 2004), and that we observed significant changes in Kir2.1 and Kir2.2 mRNA and protein levels, it was interesting to check whether the mRNA level for the SAP97 regulatory protein also changed in DCM. Both the Open Array approach and the classical qRT-PCR study on a larger set of samples indicated downregulation of SAP97 mRNA expression in DCM samples (not shown). Using the Open Array system, we measured a $27 \%$ decrease in SAP97 mRNA levels in ventricular samples of DCM patients relative to donors, similar to the decreased Kir2.2 mRNA expression. Then we validated the differences in the relative SAP97 mRNA levels in 31 control and 17 DCM samples using a different primer set (as listed in the Supplementary data, ${ }^{2}$ Tables S2 and S3). SAP97 mRNA expression was reduced by $34 \%$ in DCM compared with that in healthy hearts (Fig. $2 c ; n=31$ (control) and $n=17$ (DCM), $p<0.05$ ).

Gene expression for SAP97 was validated by qRT-PCR. The SAP97 mRNA level decreased significantly in DCM patients using the Open Array method ( $n=12$ (control) and $n=12$ (DCM)) and qRT-PCR. Furthermore, we observed robust age-dependent changes in SAP97 mRNA expression even in donor hearts when we compared 31 healthy and 17 DCM samples (Figs. $2 c$ and $2 d$ ). The SAP97 mRNA level decreased approximately $50 \%$ at an age of
40 years and higher. SAP97 mRNA levels were high at ages between 12-40 years in control cardiac ventricles and decreased by $52 \%$ in DCM patients. After 40 years of age, however, the differences in the SAP97 mRNA levels diminished between the control and DCM hearts.

\section{Kir2.x and SAP97 colocalize in both control and DCM human ventricles}

Based on the robust changes in Kir2.x and SAP97 mRNA expression in DCM versus normal hearts, we hypothesized that SAP97 binding to Kir2x isoforms and the distribution of their complexes might have changed in cardiomyocytes of DCM hearts. We used indirect immunofluorescence to address the potential differences in the distribution of SAP97-Kir2.x complexes in DCM. Using isoform-specific antibodies, we detected Kir2.1, Kir2.2, Kir2.3, and SAP97 in the sarcolemma. Lining up with qRT-PCR and immunoblot data (Figs. 2 and 3), immunofluorescent visualization of Kir2.1 clearly showed more intense immunostaining in DCM hearts than in the control cryosections (Supplementary data, ${ }^{2}$ Fig. S1). On the other hand, Kir2.2 and SAP97 clearly exhibited less intense immunofluorescence in DCM compared with the healthy heart ventricular sections (Figs. $4 a$ and $4 b$ ).

Double immunofluorescence showed the colocalization of SAP97 with Kir2.1 or Kir2.2 isoforms in cardiomyocytes of ventricular tissues in both control and DCM hearts. Although the distribution 
Fig. 3. Differentially altered expression of Kir2.x isoforms in dilated cardiomyopathy (DCM). (a) Representative immunoblots of membrane proteins extracted from ventricles of 2 healthy control and 6 DCM patients. (b) Immunoblots were subjected to densitometry for semiquantitative determination of relative expression levels of Kir2.x isoforms normalized to GAPDH levels. (c) Kir2.x isoforms from Western blot analysis normalized to $\alpha$-actin levels. Values are expressed as the mean $\pm \operatorname{SEM}\left(n_{\mathrm{CONT}}=10\right.$ and $\left.n_{\mathrm{DCM}}=10\right) ;{ }^{*}, p<0.05$.

a

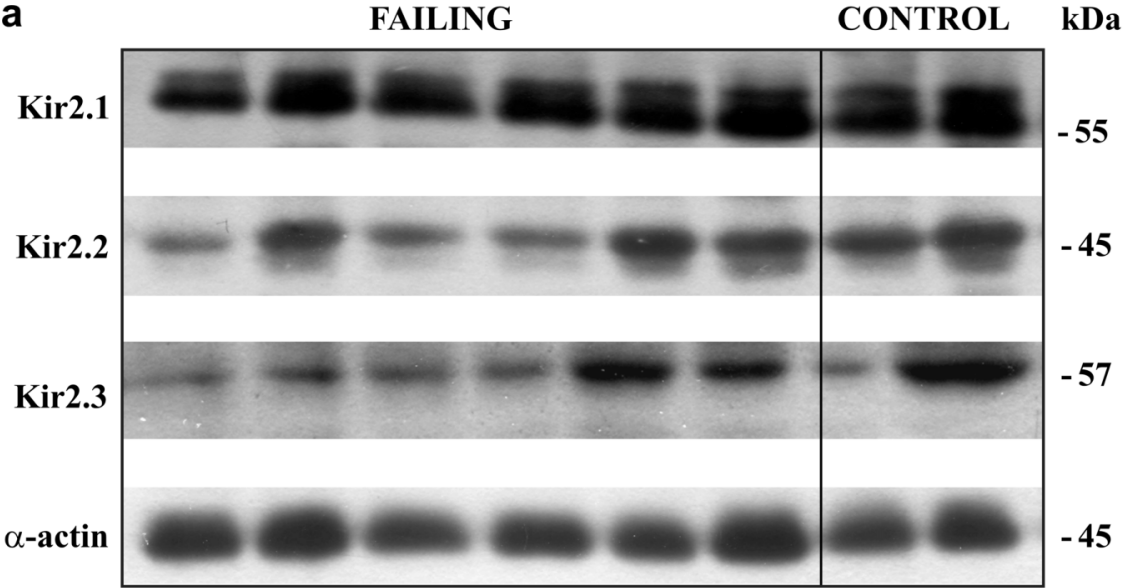

b

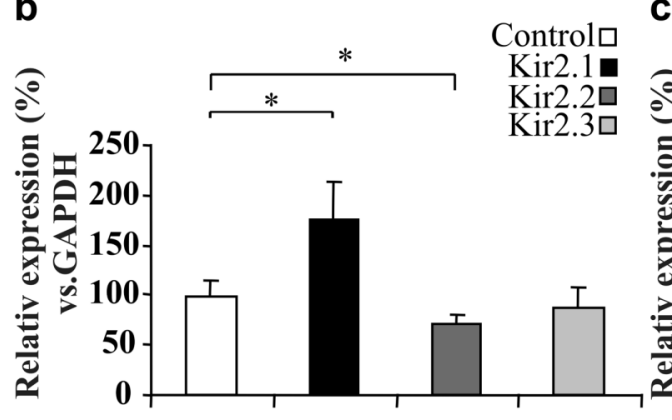

C

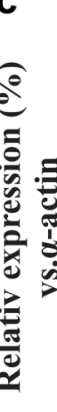

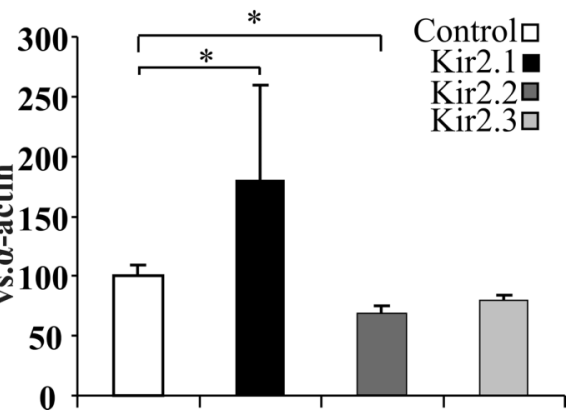

of Kir2.1 and SAP97 partially overlapped in the intercalated discs of control sections, their colocalization was more obvious in failing human ventricles, as judged by the number and intensity of merged yellow spots (Supplementary data, ${ }^{2}$ Fig. S1). Kir2.2 also colocalized at the optical level of confocal microscopy with SAP97 in both control and failing samples, but the expression pattern was different in healthy and DCM heart sections (Figs. $4 a$ and $4 b$ ). The differences in the distribution of merged Kir2.x and SAP97 yellow spots in the diseased tissue section suggest that the intracellular structures may be disorganized or disrupted in cardiomyocytes of DCM patients.

We concluded that the altered distribution of Kir2.x and SAP97 complexes revealed by immunofluorescence may be due to changes in assembly of Kir2.x heteromers at the plasma membrane of DCM cardiomyocytes.

\section{Altered inward rectifier current density in the heart of DCM patients}

During the last decade a few publications have concluded from the altered AP shape in DCM that the properties of the $I_{\mathrm{K} 1}$ current could be changed (Koumi et al. 1995). Therefore, we studied the $I_{\mathrm{K} 1}$ current in human cardiomyocytes derived from the heart of healthy donors and DCM patients. We measured $I_{\mathrm{K} 1}$ by the wholecell patch-clamp technique in isolated ventricular myocytes, as shown in Fig. 5.

The $I_{\mathrm{K} 1}$ current was recorded by applying $300 \mathrm{~ms}$ long depolarizing voltage pulses in the voltage range of -140 to $0 \mathrm{mV}$ with $3 \mathrm{~s}$ pulse intervals from the holding potential of $-90 \mathrm{mV}$. $I_{\mathrm{K} 1}$ was measured as the steady-state current at the end of the test pulse. Representative current traces and the density of $I_{\mathrm{K} 1}$ in ventricular myocytes obtained from healthy $(n=31)$ and DCM diseased hearts (representative cells $n=4$ ) are shown in Figs. $5 a$ and $5 b$. The diseased data are from 2 representative families.

At $-60 \mathrm{mV}, I_{\mathrm{K} 1}$ density was moderately lower in the healthy donor cardiomyocytes than in DCM human ventricular myocytes (Fig. $5 a$ and $5 b$ ). Steady-state inward $I_{\mathrm{K} 1}$ density (Fig. $5 c$ ) was reduced in cells isolated from DCM ventricles compared with healthy myocardium. Contrary to the inward component, the outward component increased in the myocytes of diseased hearts, although these data did not reach the level of statistical significance. However, we must emphasize as a limitation of our study the small number of examined myocytes from diseased hearts $(n=4)$. Data are the mean \pm SEM. The tendency of the outward component of $I_{\mathrm{K} 1}$ to be increased (Fig. $5 d$ ) supports the hypothesis that the expression pattern of Kir2.x isoforms might have changed in the plasma membrane of the diseased cardiomyocytes. The altered heteromeric association of these Kir2.x channels between healthy and DCM cardiomyocytes may explain the increased outward component.

\section{Discussion}

To address the role of potassium channels in the pathomechanism of DCM, we compared the expression pattern of genes encoding the 1-pore Kir2.x channels in DCM and donor hearts, and levels of the associated protein SAP97 were measured. For this purpose, cardiac left ventricular tissue samples were obtained from patients with DCM $(n=17)$ and from healthy donors $(n=31)$. Our major findings were the following: $(i)$ we observed increased expression of Kir2.1 mRNA and protein and Kir2.3 mRNA, as opposed to significantly decreased levels of Kir2.2 and SAP97 mRNA and proteins in DCM patients compared with healthy control 
Fig. 4. Immunofluorescence of Kir2.2 and synapse-associated protein 97 (SAP97) colocalization. (a) The Kir2.2 channel colocalizes with SAP97 anchoring protein in the intercalated discs of healthy myocytes. To label the nucleus, $4^{\prime}, 6$-diamidino-2-phenylindole was used. (b) Cross-section of left ventricle shows less intense fluorescence in failing human ventricle compared with the control.

a

CONTROL
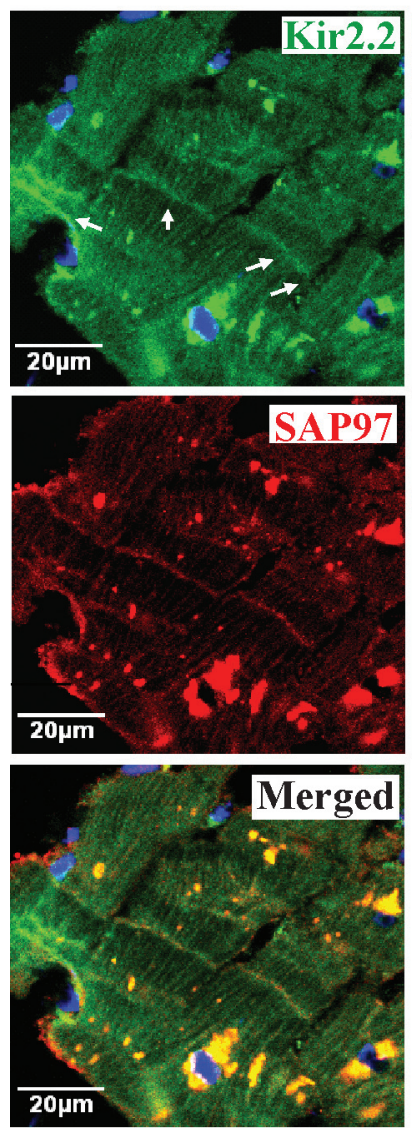

DCM
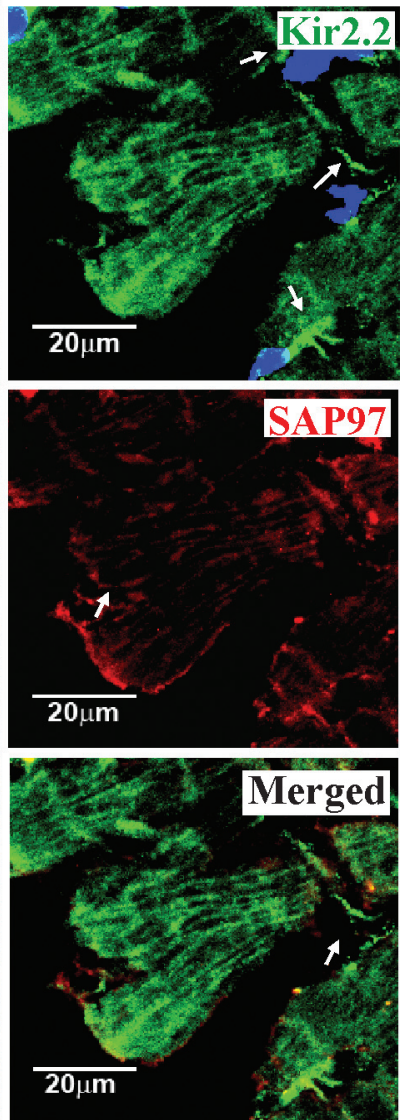

b
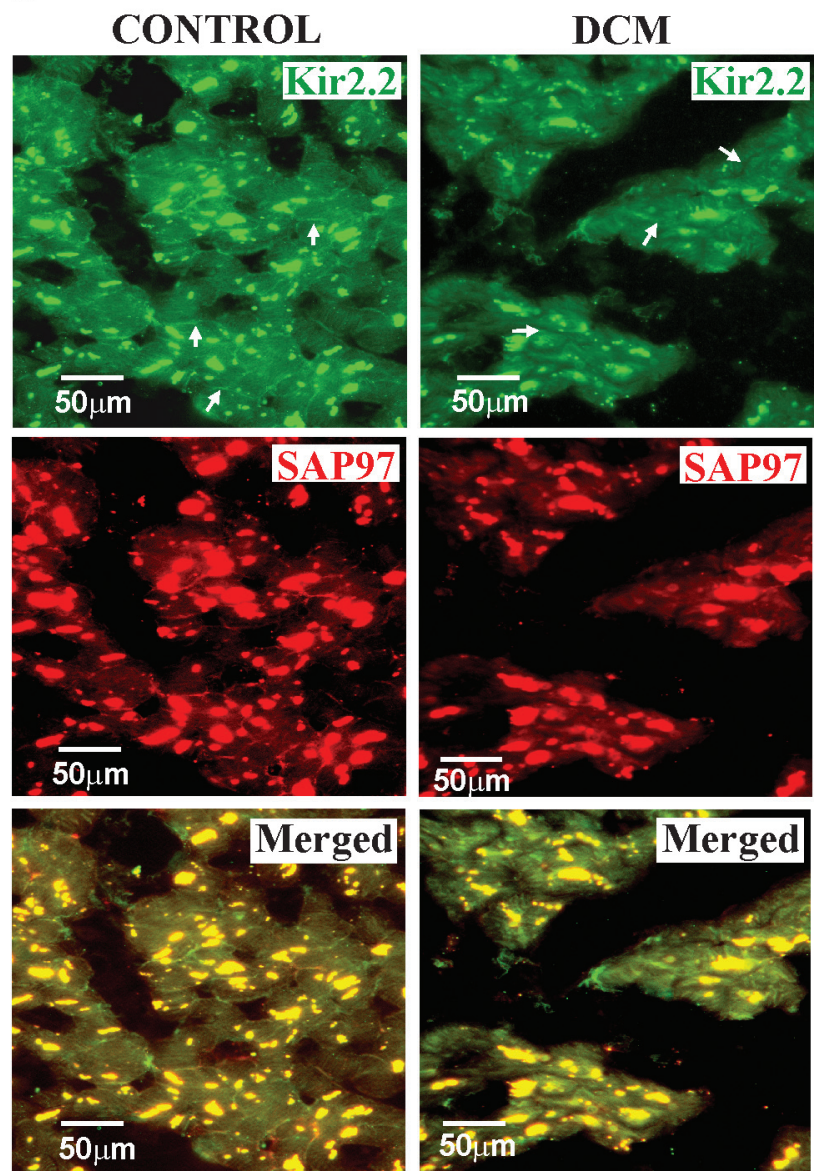

samples; (ii) immunofluorescence revealed changes in the tissue distribution of Kir2.x subunits and in their co-localization with SAP97; and (iii) we showed for the first time that the gene for SAP97 exhibits an age-dependent expression in healthy hearts, and that other genes also have a temporally regulated expression pattern altered in cardiomyopathy.

Comparing the relative gene expression for Kir and 2-pore ion channels in ventricles, we observed decreased gene expression for Kir2.2, Kir6.1, and SUR2 but, interestingly, the mRNA level increased for Kir2.1, Kir2.3, and Kir2.4 in DCM patients compared with the healthy donors (Fig. 2). Other authors have shown similar decreases in DCM for Kir6.1, which is known to be involved in the maintenance of vascular tone of microvessels (Borlak and Thum 2003; Soltysinska et al. 2009). However, in this study we have focused especially on the investigation of the gene expression changes underlying the $I_{\mathrm{K} 1}$ current. Based on our data, and considering the reported contribution of 1-pore channels to $I_{\mathrm{K} 1}$ current properties, we hypothesize that the decreased expression of Kir2.2 and the regulatory subunit SAP97 may account in large part for the decreased $I_{\mathrm{K} 1}$ current in DCM. We propose that the observed Kir2.1 and Kir2.3 upregulation may serve as a compensatory mechanism to avoid the detrimental decrease of $I_{\mathrm{K} 1}$ in cardiac disease.

\section{Outward components of the $I_{K 1}$ current is elevated in DCM}

Our hypothesis is supported by the following data from the literature. Previously, Koumi et al. (1995) reported that the $I_{K 1}$ current decreases in cardiomyocytes with DCM. It is known that

$I_{\mathrm{K} 1}$ has an influence on the depolarization and repolarization phases of AP. In phase 0 , the $\mathrm{Na}^{+}$current is dominant over $I_{\mathrm{K} 1}$, whereas $I_{\mathrm{K} 1}$ and other voltage-gated potassium currents are dominant in repolarization phases 1-4 in cardiomyocytes. In phases 0 , 3 , and $4, I_{\mathrm{K} 1}$ underlying by Kir2.x channels serves as a major current. As demonstrated by Warren et al. (2003), $I_{\mathrm{K} 1}$ properties are determined mainly by rectification and $\left[\mathrm{K}^{+}\right]_{\mathrm{o}}$ sensitivity of the Kir2.1 isoform when Kir2.x heteromeric channels are formed. Furthermore, the outward components are higher in the left ventricle than in the atria or right ventricle (Dhamoon and Jalife 2005). It has also been recently shown that the $I_{\mathrm{K} 1}$ current formed by Kir2.1 channels displays strong inward rectification, but Kir2.3 inward rectification is incomplete and negative slope-conductance is noticeably less steep in an in vivo guinea pig model and in a rabbit model (Lodge and Normandin 1997; Warren et al. 2003; Yan et al. 2005; Rose et al. 2005). Further, when Kir2.x stable transformants were used to study the influence of homo- and heteromeric associations on $I_{\mathrm{K} 1}$ current density, it was found that among the homomers, Kir2.1 produced the highest outward component, which decreased when Kir2.1 formed heteromers with other Kir2.x subunits (Schram et al. 2003; Muňoz et al. 2007). The importance of Kir2.1 was also supported by the observation that Kir2.1 $1^{-1}$ knockout mice did not exhibit measurable $I_{\mathrm{K} 1}$ (Zaritsky et al. 2001).

In our study, the expression level exhibited variability for Kir2.3, significantly decreased for Kir2.2, but increased for Kir2.1 mRNA and protein levels in DCM patients compared with healthy donors. These data are consistent with earlier reports on the 
Fig. 5. Alteration of inward rectifier currents $\left(I_{\mathrm{K} 1}\right)$ in the ventricular cardiomyocytes of dilated cardiomyopathy (DCM) patients from representative families. Original current traces recorded from $(a)$ healthy and $(b)$ DCM ventricular myocytes at a test potential ranging from -90 to $0 \mathrm{mV}$. (c) Steady-state inward $\mathrm{I}_{\mathrm{K} 1}$ current density is measured in cells isolated from DCM compared with healthy myocardium (at a test potential from -140 to $0 \mathrm{mV}$; inset shows the applied pulse protocol). (d) The outward component of $I_{\mathrm{K} 1}$ tends to increase in DCM, but the differences from healthy controls are not statistically significant. Data are expressed as the mean \pm SEM.

a

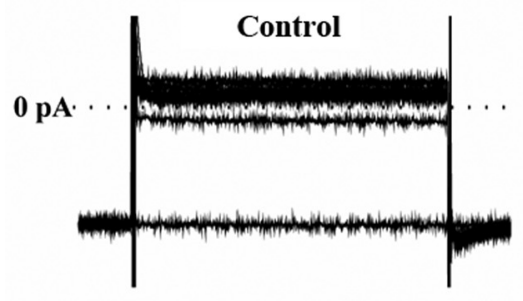

b

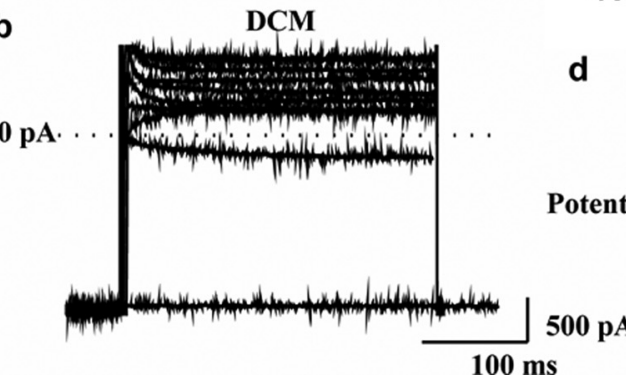

C
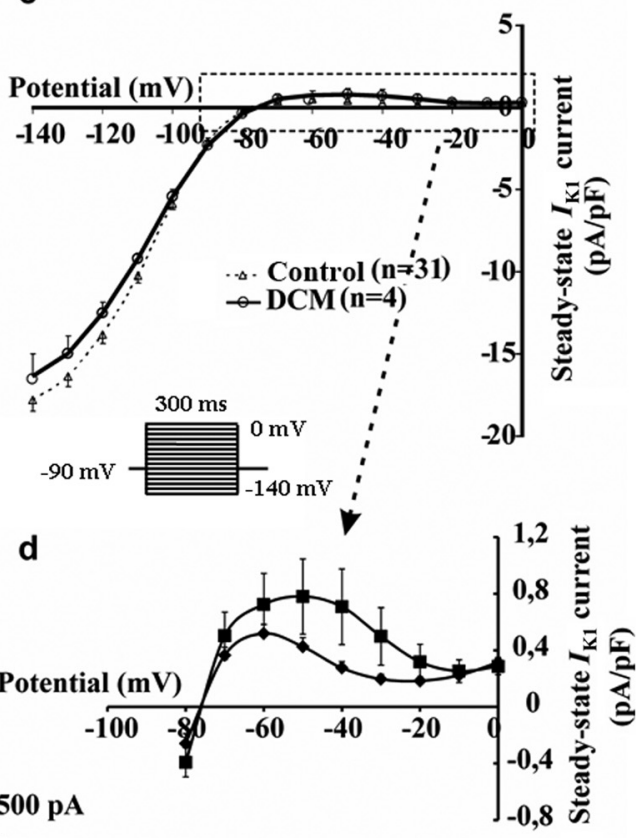

increase of Kir2.1 mRNA levels in end-stage heart failure of DCM or ischemic origin compared with donors (Borlak and Thum 2003; Soltysinska et al. 2009). Immunofluorescence and Western blot analysis also revealed decreased expression of Kir2.2 and Kir2.3, but increased deposition for Kir2.1 in the sarcolemma from DCM hearts (Figs. $3 a-3 c, 4 a$, and $4 b$ ). One feasible explanation for the pathomechanism may be that the altered gene expression and tissue distribution of Kir2.x channels contribute to the altered $I_{\mathrm{K} 1}$ current in DCM cells. Thus, we hypothesize that the increased ratio of Kir2.1 homomers or heteromers relative to all other Kir2.x homomer and heteromer ion channels translocated to the sarcolemma may account, at least in part, for the increased outward component during the progression of the disease. However, further investigations are required to prove this hypothesis.

\section{Kir2.2 isoform expression compared with other Kir2.x} expression in DCM

Koumi et al. (1995) detected a 50\% decrease in whole-cell current slope conductance of $I_{\mathrm{K} 1}$ in ventricular myocytes of DCM patients versus donors. The AP had a longer duration and a slow repolarization phase with a low resting membrane potential. Kir2.2-/knockout mice displayed a $50 \%$ reduction in $I_{\mathrm{K} 1}$ relative to that of the wild-type (Zaritsky et al. 2001), indicating that, apart from Kir2.1, Kir2.2 also highly contributes to $I_{\mathrm{K} 1}$. In our study, we found that the mRNA levels were significantly reduced, not only for Kir2.2 but also for SAP97 in the ventricle of DCM patients compared with donors, and the same was true for the protein level of Kir2.2. Taken together, the data suggest that the declined currents in the plateau and terminal phase of AP could be due to the decreased expression of these ion channels and SAP97.

\section{Decreased SAP97 associated with Kir2.2}

Ion channels are mobile molecules that can bind different regulatory factors, and their mobility can diminish with anchoring proteins in atrial cells. MAGUK proteins such as SAP97 are known to associate with Kir2.x isoforms in heart and brain samples
(Leonuodakis et al. 2000; Vaidyanathan et al. 2010). In line with these reports, our immunofluorescence data showed that the Kir2.x channels colocalize with SAP97. Furthermore, we provided evidence that human SAP97 mRNA has an age-dependent expression in donor samples. Namely, SAP97 mRNA expression in healthy donor ventricles is 2 times higher at a younger age (between 10-40 years) than at an older age of life. This dramatic age-dependent decline was characteristic only of the control tissues and was not observed in DCM samples. In fact, samples of both young and old DCM patients equally showed reduced mRNA levels similar to that of old healthy donors. The largest change, over $50 \%$ in the mRNA expression, was seen in middle-aged patients (31-50 years) versus donors. However, the difference between healthy and DCM samples disappeared above the age of 40 years.

The endogenous Kir2.x channels associate with SAP97, specifically with the C-terminal amino acids, forming signalling complexes (Leonuodakis et al. 2000). Kir2.1 strongly binds SAP97, and they show colocalization near the T-tubules. In donor samples, we also demonstrated colocalization of SAP97 with Kir2.2, while only partial colocalization was seen with Kir2.1 and Kir2.3 (not shown) in the plasma membrane. In agreement with the data of Dhamoon and Jalife (2005), the immunosignal for Kir2.1 was localized in the intercalated discs and the T-tubules. Kir2.2 was found mostly in the intercalated discs and partly at the lateral side of myocytes in the ventricle. In DCM samples, Kir2.2 decreased dramatically and the immunosignal for SAP97 also decreased in parallel. Furthermore, only partial co-localization was seen between Kir2.2 and SAP97 in the healthy plasma membrane, which decreased in DCM ventricles. On the other hand, the overlap between Kir2.2 and SAP97 immunofluorescence became more obvious, suggesting a better association of the 2 subunits (compare Fig. $4 a$ and Supplementary data, ${ }^{2}$ Fig. S1). These variations of ion channels in the cardiomyopathic heart raise the possibility that the complexes of assembled Kir2.x components differ in stoi- 
chiometry and (or) structure from those in healthy hearts. The SAP97 and Kir ion channels may be novel target molecules in the diagnosis and effective treatment of cardiomyopathy.

\section{Acknowledgements}

This work was supported by grants from the Hungarian Scientific Research Fund (OTKA CNK-77855, K-82079, K-75818, and NK-104331), the National Office for Research and Technology - Ányos Jedlik and Baross Programmes (NKFP_07_01-RYT07_AF and REG-DA-09-2-20090115-NCXINHIB), the National Development Agency co-financed by the European Regional Fund (TAMOP-4.2.2-08/1-2008-0013, TAMOP4.2.1/B-09/1/KONV-2010-0005, and TAMOP-4.2.2/B-10/1-2010-0012), the Hungarian Academy of Sciences, Hungary-Romania CrossBorder Co-operation Programme (HU-RO_TRANS-MED and HU-RO_CARDIOPOL projects), and the German-Hungarian Research Cooperation DFG Grant (436 UNG 113/176/0-1). The authors thank Dr. Ferhan Ayaydin and Ms. Zsuzsanna Kószó for helping with the confocal microscopy study and Dr. Ferenc Ötvös for discussion. We also thank János Z. Kelemen, Zoltán Bódi, and Lajos Csincsik for mRNA work and Klaudia Kávai, Anikó Simon Ferencné, Katalin Hegedủs, and Maria Tóthné for excellent technical support.

\section{References}

Anumonwo, J.M., and Lopatin, A.N. 2010. Cardiac strong inward rectifier potassium channels. J. Mol. Cell. Cardiol. 48: 45-54. doi:10.1016/j.yjmcc.2009.08. 013. PMID:19703462.

Barrans, J.D., Allen, P.D., Stamatiou, D., Dzau, V.J., and Liew, C.C. 2002. Global gene expression profiling of end-stage dilated cardiomyopathy using human cardiovascular based cDNA microarray. Am. J. Pathol. 160: 2035-2043. doi: 10.1016/S0002-9440(10)61153-4. PMID:12057908.

Borlak, J., and Thum, T. 2003. Hallmarks of ion channel gene expression in end-stage heart failure. FASEB J. 17: 1592-1608. doi:10.1096/fj.02-0889com. PMID:12958166.

Csanády, M., Faragó, M., Forster, T., Hőgye, M., and Piros, Gy . 1991. Study of the course of inheritance of dilated familial cardiomyopathy. Eur. Heart J. 12: 191.

Dhamoon, A.S., and Jalife, J. 2005. The inward rectifier current $\left(I_{\mathrm{K} 1}\right)$ controls cardiac excitability and and is involved in arrhythmogenesis. Heart Rhythm, 2: 316-324. doi:10.1016/j.hrthm.2004.11.012. PMID:15851327.

Gaborit, N., Le Bouter, S., Szuts, V., Varro, A., Nattel, S., Escande, D., and Demolombe, S. 2007. Regional and Tissue Specific Transcript Signatures of Ion Channel Genes in the Normal Human. J. Physiol. 582: 675-693. doi:10. 1113/jphysiol.2006.126714. PMID:17478540.

Gaborit, N., Wichter, T., Varró, A., Szűts, V., Lamirault, G., Eckardt, L., Paul, M., Breithardt, G., Schulze-Bahr, E., Escande, D., Nattel, S., and Demolombe, S. 2009. Transcriptional profiling of ion channel genes in Brugada syndrome and other right ventricular arrhythmogenic diseases. Eur. Heart J. 30: 487496. doi:10.1093/eurheartj/ehn520. PMID:19029124.

Hibino, H., Inanobe, A., Furutani, K., Murakami, S., Findlay, I., and Kurachi, Y. 2010. Inwardly rectifying potassium channels: their structure, function, and physiological roles. Physiol. Rev. 90: 291-366. doi:10.1152/physrev.00021. 2009. PMID:20086079.

Jefferies, J.L., and Towbin, J.A. 2010. Dilated cardiomyopathy. Lancet, 375: 752762. doi:10.1016/S0140-6736(09)62023-7. PMID:20189027.

Jost, N., Acsai, K., Horváth, B., Bányász, T., Baczkó, I., Bitay, M., Bogáts, G., and Nánási, P.P. 2009. Contribution of IKr and IK1 to ventricular repolarization in canine and human myocytes: is there any influence of action potential duration? Basic Res. Cardiol. 104: 33-41. doi:10.1007/s00395-008-0730-3. PMID: 18604626.

Karle, C.A. Zitron, E., Zhang, W. Wendt-Nordahl, G, and Kathöfer, S. 2002. Cardiac inwardly-rectifying $\mathrm{K}^{+}$channel $\mathrm{Kir}_{2.1 \mathrm{~b}}$ is inhibited by direct protein kinase C-dependent regulation in human isolated cardiomyocytes and in an expression System. Circulation, 106: 1493-1499. doi:10.1161/01. CIR.0000029747.53262.5C. PMID:12234954.

Koumi, S., Backer, C.L., and Arentzen, C.E. 1995. Characterization of inwardly rectifying $\mathrm{K}^{+}$channel in human cardiomyocytes. Alterations in channel behavior in myocytes isolated from patients with idiopathic dilated cardiomyopathy. Circulation, 92: 164-174. doi:10.1161/01.CIR.92.2.164. PMID:7600647.

Kubo, Y., Adelman, J.P., Clapham, D.E., Jan, L.Y., Karschin, A., Kurachi, Y., Lazdunski, M., Nichols, C.G., Seino, S., and Vandenberg, C.A. 2005. International Union of Pharmacology. LIV. Nomenclature and molecular relationships of inward rectifying potassium channels. Pharmacol. Rev. 57: 509-526. doi:10.1124/pr.57.4.11. PMID:16382105.

Leonoudakis, D., Mailliard, W.S., Wingerd, K.L., Clegg, D.O., and
Vandenberg, C.A. 2000. Inward rectifier potassium channel Kir2.2 is associated with synapse-associated protein SAP97. J. Cell Sci. 114: 987-998. PMID: 11181181

Leonoudakis, D., Conti, L.R., Radeke, C.M., McGuire, L.M., and Vandenberg, C.A. 2004. A multiprotein trafficking complex composed of SAP97, CASK, Veli, and Mint1is associated with inward rectifier Kir2 potassium channels. J. Biol. Chem. 279: 19051-19063. doi:10.1074/jbc.M400284200. PMID:14960569.

Livak, K.J., and Schmittgen, T.D. 2001. Analysis of relative gene expression data using real time quantitative PCR and the 2(-Delta Delta C(T)) method. Methods, 25: 402-408. doi:10.1006/meth.2001.1262. PMID:11846609.

Lodge, N.J., and Normandin, D.E. 1997. Alterations in $I_{\mathrm{to}}, I_{\mathrm{Kr}}$ and $I_{\mathrm{k} 1}$ density in the BIO TO-2 strain of Syrian myopathic hamsters. J. Mol. Cell. Cardiol. 29: 3211-3221. doi:10.1006/jmcc.1997.0548. PMID:9441828.

Marban, E. 2002. Cardiac channelopathies. Nature, 415: 213-218. doi:10.1038/ 415213a. PMID:11805845

Muňoz, V., Vaidyanathan, R., Tolkacheva, E.G., Dhamoon, A.S., Taffet, S.M., and Anumonwo, J.M.B. 2007. Kir2.3 isoform confers $\mathrm{pH}$ sensitivity to heteromeric Kir2.1/Kir2.3 channels in HEK293 cells. Heart Rhythm, 4: 487-496. doi:10.1016/ j.hrthm.2006.12.033. PMID:17399639.

Pfaffl, M.W. 2001. A new mathematical model for relative quantification in real-time RT-PCR. Nucleic Acids Res 29: e45. doi:10.1093/nar/29.9.e45. PMID: 11328886.

Piecha, D., Muratoglu, S., Mörgelin, M., Hauser, N., Studer, D., Kiss, I., Paulsson, M., and Deák, F. 1999. Matrilin-2, a large, oligomeric matrix protein, is expressed by a great variety of cells and forms fibrillar networks. J. Biol. Chem. 274: 13353-13361. doi:10.1074/jbc.274.19.13353. PMID:10224097.

Rook, M.B. 2007. Physiologic function of I(K1) requires a combination of Kir2 isoforms. Heart Rhythm, 4: 497-499. doi:10.1016/j.hrthm.2006.12.041. PMID: 17399640.

Rose, J., Armoundas, A.A., Tian, Y., DiSilvestre, D., Burysek, M., Halperin, V., O'Rourke, B., Kass, D.A., Marban, E., and Tomaselli, G.F. 2005. Molecular correlates of altered expression of potassium currents in failing rabbit myocardium. Am. J. Physiol. Heart Circ. Physiol. 288: H2077-H2087. doi:10.1152/ ajpheart.00526.2003. PMID:15637125.

Schram, G., Pourrier, M., Wang, Z., White, M., and Nattel, S. 2003. Barium block of Kir2 and human cardiac inward rectifier currents: evidence for subunitheteromeric contribution to native currents. Cardiovasc. Res. 59: 328-338. doi:10.1016/S0008-6363(03)00366-3. PMID:12909316.

Soltysinska, E., Olesen, S.P., Christ, T., Wettwer, E., Varró, A., Grunnet, M., and Jespersen, T. 2009. Transmural expression of ion channels and transporters in human nondiseased and end-stage failing hearts. Pflugers Arch. 459: 11-23. doi:10.1007/s00424-009-0718-3. PMID:19768467.

Szabó, G., Szentandrássy, N., Bíró, T., Tóth, B.I., Czifra, G., Magyar, J., Bányász, T., Varró, A., Kovács, L, and Nánási, P.P. 2005. Asymmetrical distribution of ion channels in canine and human left-ventricular wall: epicardium versus midmyocardium. Pflugers Arch. 450: 307-316. doi:10.1007/s00424-005-1445-Z. PMID:15952036.

Szentadrassy, N., Banyasz, T., Biro, T., Szabo, G., Toth, B.I., Magyar, J., Lazar, J., Varro, A., Kovacs, L., and Nanasi, P.P. 2005. Apico-basal inhomogeneity in distribution of ion channels in canine and human ventricular myocardium. Cardiovasc. Res. 65: 851-860. doi:10.1016/j.cardiores.2004.11.022. PMID:15721865.

Vaidyanathan, R., Taffet, S.M., Vikstrom, K.L., and Anumonwo, M.B.J. 2010. Regulation of cardiac inward rectifier potassium current (I(K1)) by synapseassociated protein-97. J. Biol. Chem. 285: 28000-28009. doi:10.1074/jbc.M110. 110858. PMID:20530486.

Virág, L., Iost, N., Papp, J.Gy., and Varró, A. 2002. Effect of $\mathrm{Ba}^{2+}$ in low concentrations on various transmembrane potassium currents in dog ventricular myocytes. J. Mol. Cell. Cardiol. 34: A67. doi:10.1016/S0022-2828(02)90994-6.

Warren, M., Guha, P.K., Berenfeld, O., Zaitsev, A., Anumonwo, J.M., Dhamoon, A.S., Bagwe, S., Taffet, S.M., and Jalife, J. 2003. Blockade of the inward rectifying potassium current terminates ventricular fibrillation in the guinea pig heart. J. Cardiovasc. Electrophysiol. 14: 621-631. doi:10.1046/j. 1540-8167.2003.03006.x. PMID:12875424.

Yan, D.H., Nishimura, K., Yoshida, K., Nakahira, K., Ehara, T., Igarashi, K., and Ishihara, K. (2005). Different intracellular polyamine concentrations underlie the difference in the inward rectifier $\mathrm{K}(+)$ currents in atria and ventricles of the guinea-pig heart. J. Physiol. 563: 713-724. PMID:15668212.

Zaritsky, J.J., Redell, J.B., Tempel, B.L., and Schwarz, T.L. 2001. The consequence of disrupting cardiac inwardly rectifying $\mathrm{K}(+)$ current $(\mathrm{I}(\mathrm{K} 1)$ ) as revealed by the targeted deletion of the murine Kir2.1 and Kir2.2 genes. J. Physiol. 533: 697710. doi:10.1111/j.1469-7793.2001.t01-1-00697.x. PMID:11410627.

Zvara, A., Szekeres, G., Janka, Z., Kelemen, J.Z., Cimmer, C., and Puskás, L.G. 2005. Over-expression of dopamine D2 receptor and inwardly rectifying potassium channel genes in drug-naive schizophrenic peripheral blood lymphocytes as potential diagnostic markers. Dis. Markers, 21: 61-69. PMID: 15920292. 